\title{
PLATE FIN AND TUBE HEAT EXCHANGER MODELING: EFFECTS OF PERFORMANCE PARAMETERS FOR TURBULENT FLOW REGIME
}

\author{
Arafat A. Bhuiyan ${ }^{1 *}$, M. Ruhul Amin ${ }^{2}$, Rezwanul Karim ${ }^{1}$ \\ and A.K.M. Sadrul Islam ${ }^{1}$ \\ ${ }^{1}$ Department of Mechanical Engineering, Islamic University of Technology (IUT) \\ Gazipur-1704, Dhaka, Bangladesh. Fax: +880 29291260 \\ *E-mail: arafat@iut-dhaka.edu \\ ${ }^{2}$ Department of Mechanical Engineering, Montana State University \\ Bozeman, MT 59717-3800, USA. Fax: (406) 994-6292
}

\begin{abstract}
In the current study, the air-side turbulent thermal and hydraulic characteristics of finned tube heat exchanger of staggered tube arrangement are simulated with steadystate solvers using ANSYS CFX12.0, a Commercial CFD code for turbulent flow regimes. The k- $\omega$ model was used to predict the turbulent flow characteristics through the finned tube heat exchanger. The level of confidence of this numerical model was based on a comparison with previous experimental data from the literature, comparing the friction factor $f$ and Colburn factor $j$, and reasonable agreement is found between the simulations and experimental data. Detailed analysis of the effect of thermal and hydraulic performance of related parameters such as longitudinal pitch, transverse pitch, and fin pitch are also critically evaluated for turbulent flow regime. The increase in the longitudinal pitch and transverse pitch causes a decrease in the heat transfer and pressure drop performance as the flow becomes free and less compact with the increase in the tube pitch. The effect of fin pitch on the heat exchanger performance demonstrates that a decrease in the fin pitch shows the opposite performance to that of the longitudinal and transverse pitches.
\end{abstract}

Keywords: Plain fin; Turbulence; Friction factor; Colburn factor; Efficiency index.

\section{INTRODUCTION}

Plate finned tube heat exchangers of plain fin form are normally used for the purposes of heating, air conditioning, ventilating, and refrigeration, as a result of their simplicity. This type of fin is normally used to increase heat transfer performance in the heat exchanger, which can be characterized by the flow pattern. For an air-cooled heat exchanger, thermal resistance is usually on the air side (Yuan, 2000). In order to increase performance and to reduce size and weight, the use of enhanced surfaces is very popular. Many attempts have been made to investigate the thermal and hydraulic characteristics of plain fin-and tube heat exchangers. Several authors (Choi, 2010; Goldstein Jr, 1976; Lu et al., 2011; Pongsoi, Pikulkajorn, Wang, \& Wongwises, 2012) have investigated the effects of the number of tube rows on staggered plate finned tube heat exchangers. Several correlations have been proposed to the effects of heat transfer and pressure drop on the performance of heat exchangers for plain fin geometry which gave predictive ability for the plain fin heat exchangers having larger tube diameter, larger longitudinal and transverse tube pitch (Eckels \& Rabas, 1987; Junqi, Jiangping, 
Zhijiu, Yimin, \& Wenfeng, 2007; Kayansayan, 1993; Şahin, Akkoca, Öztürk, \& Akilli, 2006; Yuan, 2000; Zhang, He, \& Tao, 2009) proposed correlations for heat transfer and friction characteristics for several geometric parameters in the thermal and hydraulic performance of a number of plain-fin heat exchangers. A number of studies (Eckels \& Rabas, 1987; Syam Sundar, Sharma, \& Parveen, 2009) have been conducted into the effect of fin spacing in the performance of fin tube heat exchangers provided test results for the investigation of the effect of fin spacing and fin length. Numerous studies have measured the heat transfer coefficient and pressure drop over an eight tube row in-lined tube array (Eckels \& Rabas, 1987; Kundu, Haji-Sheikh, \& Lou, 1991; Launder \& Massey, 1978; Şahin et al., 2006; Tang, Min, Xie, \& Wang, 2009) . The experimental data available up to 1994 has been reviewed in the book by Nakonieczny (2006). Yuan (2000) reported airside performance for 15 samples of plain fin-and-tube heat exchangers. They examined the effects of several geometrical parameters, including the number of tube rows, fin spacing and fin thickness.

Several numerical studies for plain fin-and-tube heat exchangers are found in the literature. Most of them concentrated on 2-D and laminar flow conditions ((Aslam Bhutta et al., 2012; Chen \& Wung, 1989; Fujii, Fujii, \& Nagata, 1984; Kundu et al., 1991; Launder \& Massey, 1978; Tutar \& Akkoca, 2004; Yuan, 2000)). Kundu et al. (1991)reported 2-D numerical results comparing with experimental data to show the influence of fin spacing on the heat transfer and pressure drop over a four-row in-line cylinder between two parallel plates for $50 \leq R e_{H} \leq 500$. It was reported that 2-D flow modeling cannot sufficiently forecast heat transfer characteristics. Due to the complicated flow structure between the fins, 3-D numerical studies tend to be difficult. Few researchers have reported 3-D modeling for plain-fin configuration in their numerical studies (Aslam Bhutta et al., 2012; Chiu \& Jang, 2009; Jang, Wu, \& Chang, 1996; Junqi et al., 2007; Kundu et al., 1991; Şahin et al., 2006; Tutar \& Akkoca, 2004). Most of these study has been conducted around the laminar to transitional flow range. Most of the study does not attempt to compare the numerical results obtained using different turbulence models with the experimental data. Therefore the suitability of any particular turbulence model for the practical applications of the plate-fin heat exchanger is not addressed. This author studied the suitability of different turbulent models, the $k-\varepsilon$ model, $R N G k$ - $\varepsilon$ model, and $k$ - $\infty$ model and finally $k$ - $\oplus$ model was considered an appropriate choice for turbulent flow (Bhuiyan, Islam, \& Amin, 2012a).This author has previously also investigated the flow characteristics for plain and wavy fin tube staggered and inline arrangements for laminar and transitional flow range (Bhuiyan et al., 2012a; Bhuiyan, Amin, \& Islam, 2012b; Bhuiyan, Islam, \& Amin, 2011). The effects of different geometric parameters such as longitudinal, pitch, transverse pitch, and fin pitch for plain fin, as well as wavy angle and wavy height for the wavy fin have also already been investigated, but all these studies were limited for laminar to the transitional range. In this study, the simulation results for plain fin, considering staggered arrangements for turbulent $\left(2100 \leq R e_{H} \leq 7000\right)$ flow range, will be investigated to determine their effect on the heat transfer and pressure drop performance based on the available experimental data of (Yuan, 2000)and as a continuation of the numerical work of the authors for laminar flow (Bhuiyan et al., 2011)and transitional flow (Bhuiyan et al., 2012a; Bhuiyan et al., 2012b). A detailed analysis of the effect of the geometrical parameters mentioned above will also be presented. 


\section{MATHEMATICAL MODEL}

This study was based on thermal transport with convective heat transfer where air is considered as the working media assuming constant properties $(k=0.0261 \mathrm{~W} / \mathrm{mK}, \mu$ $=1.831 \times 10-05 \mathrm{Ns} / \mathrm{m}^{2}, \rho=1.185 \mathrm{kgm}^{-3}$ ). Assumptions are: 1) Steady 3-D incompressible flows, 2) No viscous dissipation and viscous work, and 3) Effects of body force and buoyancy are neglected. For turbulent flow solutions, the $k-\omega$ turbulent model is used. The conservation laws for mass, momentum and the energy equations are given below:

$$
\begin{gathered}
{\left[\frac{\partial u_{i}}{\partial x_{i}}=0\right]} \\
\rho\left(u_{j} \frac{\partial u_{i}}{\partial x_{j}}\right)=-\frac{\partial p}{\partial x_{i}}+\frac{\partial}{\partial x_{j}}\left[\left(\mu+\mu_{T}\right)\left(\frac{\partial u_{i}}{\partial x_{j}}+\frac{\partial u_{j}}{\partial x_{i}}\right)\right] \\
\rho C_{P}\left(u_{j} \frac{\partial T}{\partial x_{j}}\right)=\frac{\partial}{\partial x_{j}}\left[\left(\lambda+\frac{\mu_{T} C_{P}}{P r_{T}}\right) \frac{\partial T}{\partial x_{j}}\right]
\end{gathered}
$$

where, $\quad \mu_{T}=$ Turbulent viscosity,

$$
\operatorname{Pr}_{T}=\text { Turbulent Prandtl number. }
$$

In the current study, $P r_{T}=0.9$ is considered as suggested by (Yuan, 2000). In the k- $\omega$ turbulent model the $\mu_{T}$ is linked to the $\mathrm{k}$ and $\omega$ via the following equation:

$$
\mu_{T}=\rho \frac{k}{\omega}
$$

where, $\quad k=$ Turbulence kinetic energy; $\omega=$ Turbulence frequency

The modified transport equations for $\mathrm{k}$ and $\omega$ can be expressed as: (Menter, 1994)

$$
\begin{gathered}
\rho\left(u_{j} \frac{\partial k}{\partial x_{j}}\right)=\frac{\partial}{\partial x_{j}}\left[\left(\mu+\frac{\mu_{T}}{\sigma_{k 3}}\right) \frac{\partial k}{\partial x_{j}}\right]+P_{k}-\beta^{\prime} \rho k \\
\rho\left(u_{j} \frac{\partial \omega}{\partial x_{j}}\right)=\frac{\partial}{\partial x_{j}}\left[\left(\mu+\frac{\mu_{T}}{\sigma_{\omega 3}}\right) \frac{\partial \omega}{\partial x_{j}}\right]+2\left(1-F_{1}\right) \rho \frac{1}{\sigma_{\omega 2} \omega} \frac{\partial k}{\partial x_{j}} \frac{\partial \omega}{\partial x_{j}}+\alpha_{3} \frac{\omega}{k} P_{k}-\beta_{3} \rho \omega^{2}
\end{gathered}
$$

where, $\mathrm{F}_{1}$ is a blending function and its value is a function of the wall distance. The model constants are given as $\alpha_{1}=5 / 9, \beta^{\prime}=0.09, \beta 1=0.075, \sigma_{k 1}=2, \sigma_{w 1}=2, \alpha_{2}=0.44$, $\beta_{2}=0.0828, \sigma_{k 2}=1, \sigma_{w 2}=1 / 0.856$ (Menter, 1994; Panse, 2005; Reddy \& Gartling, 2010).

\section{COMPUTATIONAL DOMAIN AND BOUNDARY CONDITIONS}

As mentioned earlier, this study is based on the experimental work of (Menter, 1994) and is a continuation of the numerical work of (Bhuiyan et al., 2012a; Bhuiyan et al., 2011)and the geometry considered for the analysis are plain fin, with inline and staggered tube arrangements. The detailed geometric dimensions are given in Table 1. The coordinate systems are shown in

Figure 1. The boundaries of the domain consist of inlet and outlet boundaries, symmetry planes and solid walls. The computational domain extends further than the heat exchangers to downstream, to reduce the numerical oscillations (Şahin et al., 2006)The major boundary conditions of the prescribed domain are given below: 
(i). Inlet: At the upstream boundary, constant velocity and constant temperature are considered;

(ii). Outlet: At the downstream end of the computational domain, Neumann boundary conditions are assumed.

(iii). Wall: A no-slip condition is considered at the solid surfaces with constant wall temperature.

(iv). Symmetry: Symmetry conditions are considered on the mid planes between two fins. This symmetry of the problem is used to model only one half of the domain for the computational purposes. Symmetry boundary conditions are prescribed at the center plane, tube center plane and the top symmetry plane.

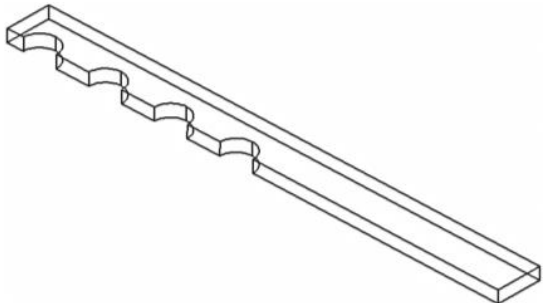

(a) Inline configuration

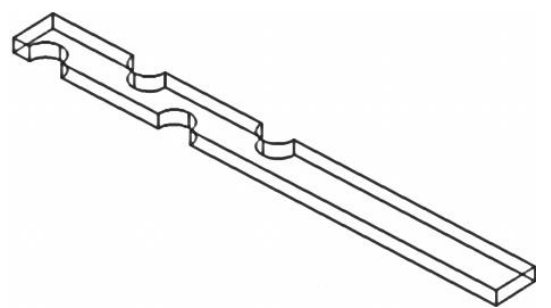

(b) Staggered configuration

Figure 1. Illustration of the main domain and coordinate system.

Table 1. Geometric dimensions of heat exchanger model (Wang, Chang, Hsieh, \& Lin, 1996).

\begin{tabular}{l|l}
\hline Parameters & Dimension \\
\hline Tube diameter $(D)$ & $9.525 \mathrm{~mm}$ \\
Longitudinal tube pitch $(L l)$ & $19.05 \mathrm{~mm}$ \\
Transverse tube pitch $(L t)$ & $25.40 \mathrm{~mm}$ \\
Fin Pitch $(F p)$ & $3.530 \mathrm{~mm}$ \\
Number of tube row $(N)$ & 4 \\
\hline
\end{tabular}

\section{SENSITIVITY ANALYSIS}

Grid sensitivity tests were made by recursive refinement and comparison between the multiple numerical results. The variation of $f$ and $j$ in the domain are investigated to determine the independence of the value of these parameters for a given number of nodes. This process was repeated for three different cases, as presented in

Table 2 for the plain fin configuration, until the variation of those parameters were negligible for different grid size, so that the numerical predictions could be regarded as grid independent. A comparatively fine grid was set for the fin and tube region, and a coarser grid was allowed in the extended portion of the geometry to conserve computational resources. It was found that an unstructured mesh system with triangular mesh containing 141700 nodes and 451756 elements is considered fine enough to resolve the flow features in all simulations. For all simulation cases, $y+$ values in the near-wall region are less than 1. 
Table 2. Different grid resolutions for the plain fin staggered configurations.

\begin{tabular}{c|cc}
\hline Case & No of nodes & No of elements \\
\hline Case-I & 91821 & 241610 \\
$*$ Case-II & 141700 & 451756 \\
Case-III & 191480 & 540402 \\
\hline
\end{tabular}

*Used in the present study.

\section{CODE VALIDATION}

As mentioned earlier, this computational study simulated the experimental work of Wang et al. (1996) for the turbulent flow range of the fin configuration, where friction factor and Colburn factor are measured for the heat exchanger.
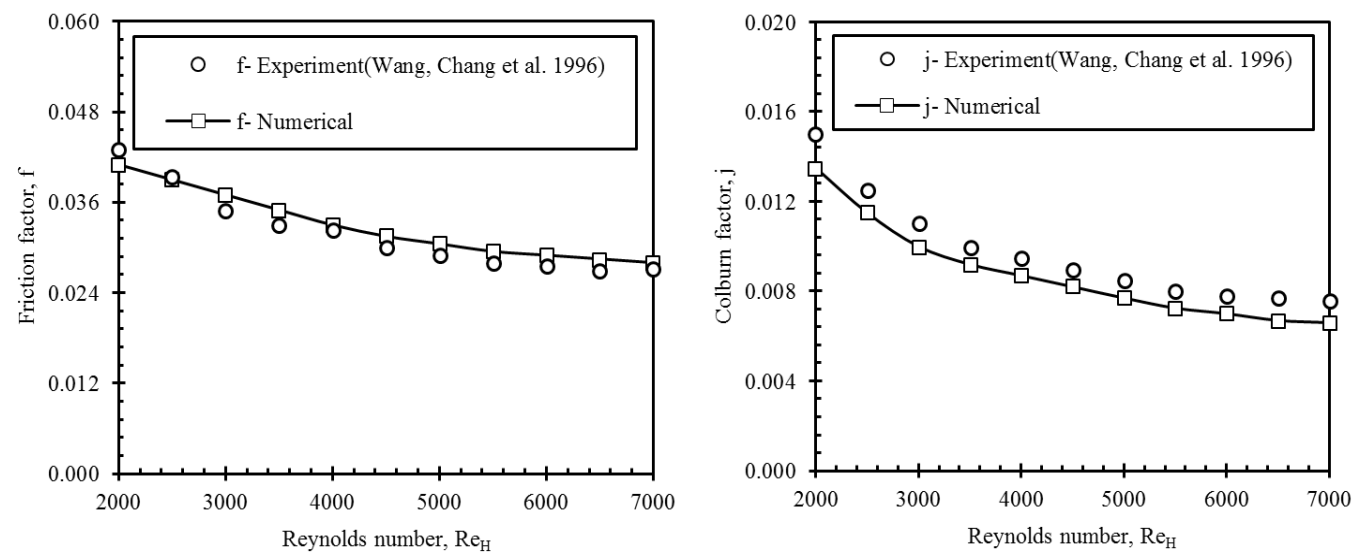

Figure 2 shows the comparison between the numerical data for $f$ and $j$ respectively with the published experimental data (Wang et al., 1996) for the turbulent flow regime. The maximum difference between the experimental data and the numerical results was less than $7 \%$ and $12 \%$ in the case of $f$ and $j$ respectively. A reasonably good agreement was found between experimental and numerical trends. It can be seen from these figures, that as the Reynolds number, $R e_{H}$, is increasing, the friction factor, $f$, and Colburn factor, $j$, are decreasing. The Reynolds number is increasing with increased turbulence, and the heat transfer and pressure drop is going downstream as observe from these figures. 

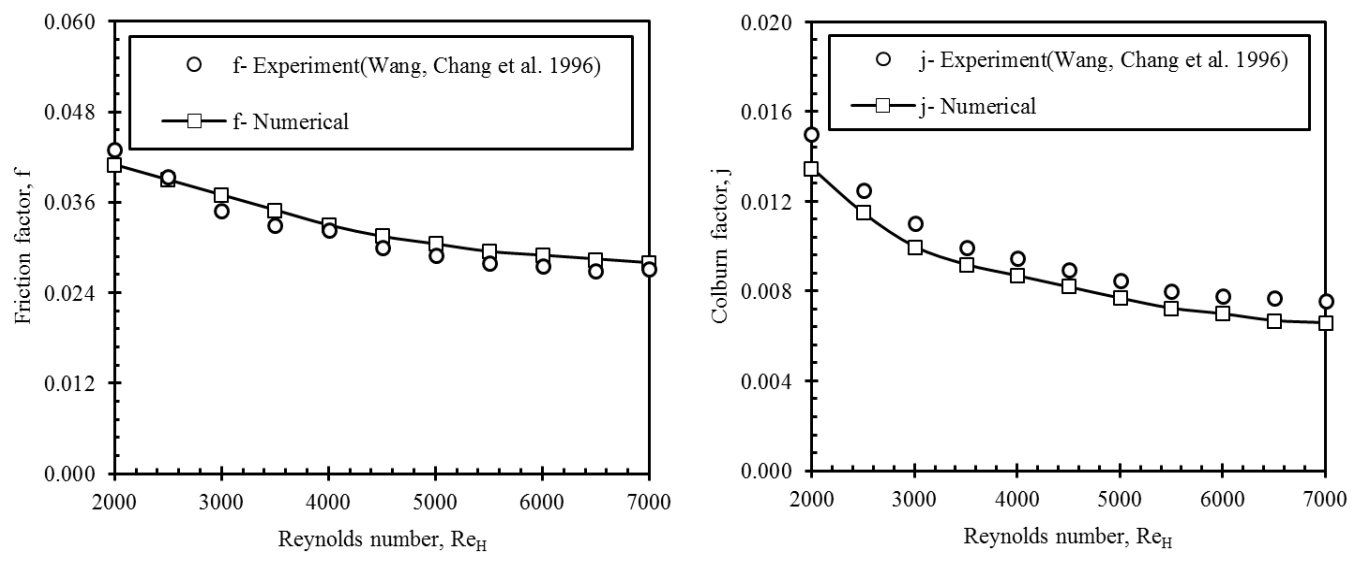

Figure 2: Comparison of the present numerical results with the experimental data (Wang et al., 1996).

\section{RESULTS AND DISCUSSION}

The current study considered the turbulent $\left(2000 \leq R e_{H} \leq 70000\right)$ flow range to investigate the flow distinction among the plain fin of two different tube arrangements and the effects of various geometrical parameters in terms of two major performance parameters namely $f$ and $j$. The $k$ - $\omega$ turbulent model was used to solve the turbulent problems considering various turbulent quantities such as the rate of dissipation of turbulent energy and turbulent viscosity. This model is widely used and is a tested turbulence model. A numerical study considering various turbulent models and their effectiveness in the transitional regime for similar geometries has been conducted recently (Bhuiyan et al., 2012a; Bhuiyan et al., 2012b).

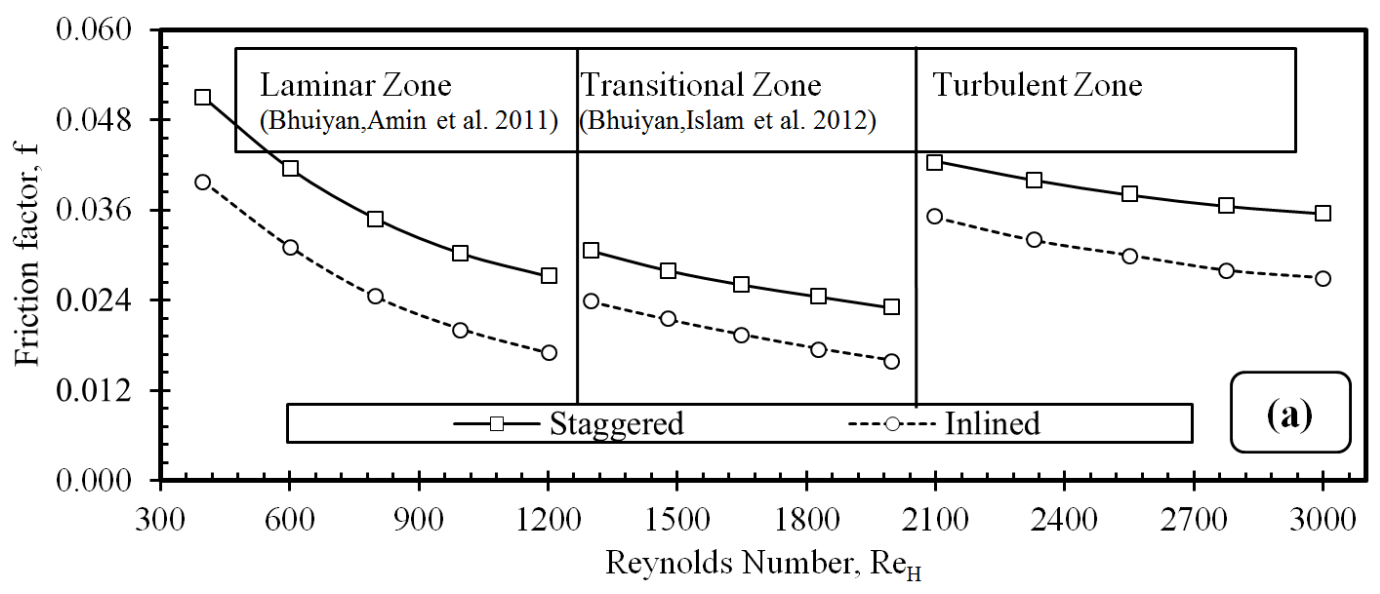



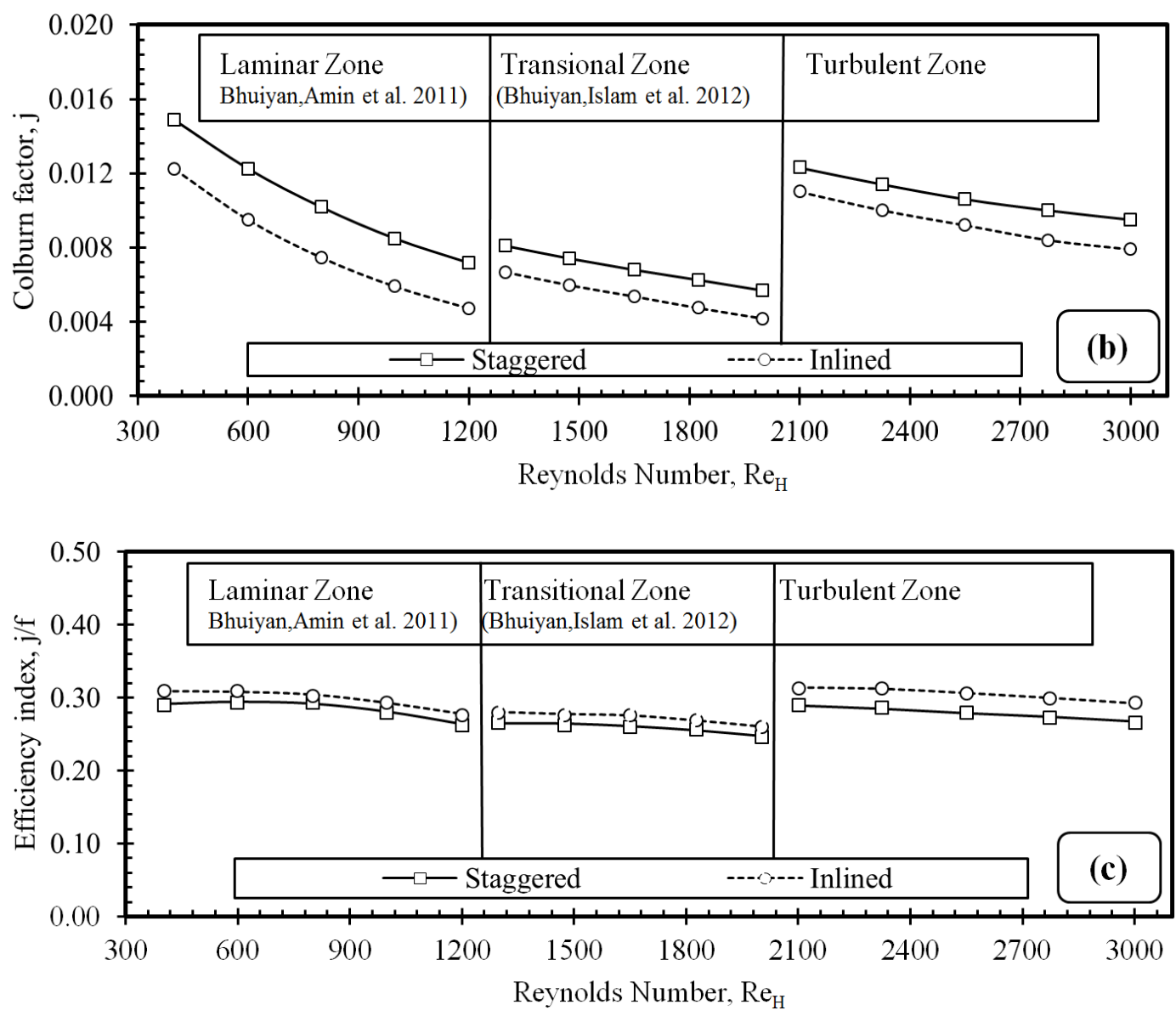

Figure 3: Flow comparison for different tube arrangement for various flow regimes.

(a) Pressure drop, (b) Heat transfer, and (c) Efficiency.

The suitability of the $k-\omega$ turbulent model has been evaluated comparing other models with the turbulent model and considerable success has been achieved in predicting performance by using this model. The distinctiveness in flow comparisons between staggered and inline arrangements have been demonstrated previously (Bhuiyan et al., 2012a; Bhuiyan et al., 2012b). For the plain fin staggered configurations flow interruption takes place on both sides of the domain. Because of the repeated interruption of the flow due to staggered tubes on both sides of the domain for this fin configuration, a smaller recirculation zone is observed at the trailing edge of the domain. The flow variation in terms of $f$ and $j$ for these two arrangements for a turbulent regime are shown in Figure 3 along with the comparison of the laminar and transition flow from (Bhuiyan et al., 2012a; Bhuiyan et al., 2012b). The trend is very similar to the general trend in friction factor and Colburn factor by Kayansayan (1993) as well as the trend observed for the laminar and transitional regime by the same author. From the plot it can be seen that the friction factor and Colburn factor tend to be almost parallel to each other. The slopes of the two parameters also generally tend to reduce as the Reynolds number is increased. It can be reported from this flow analysis that for the plain fin staggered arrangements, a higher difference in heat transfer and pressure drop is found when compared with the plain fin in-line configurations. This is due to the tube arrangement which provides flow obstructions and thus generates a pressure drop in the related domain. 
The effect of various geometrical parameters which are essential in design and development have not been previously explored in detail. The numerical results reported by Bhuiyan et al. (2012a); (Bhuiyan et al., 2012b) explore flow characteristics and the effects of different geometrical parameters on thermal and hydraulic performance in the laminar and transition range. This study explores a few of those particular parameters for the plain fin staggered arrangement in the turbulent flow regime in order to support designers in choosing better geometry. In order to study the effects of longitudinal pitch, three test cases are considered, with all the other parameters being kept constant for the studied configuration. The effects of longitudinal pitch have been studied in numerical detail for laminar and turbulent regimes. The effects are studied with the help of pressure drop characteristics represented by the friction factor and heat transfer characteristics represented by the Colburn factor.

Figure 4(a) shows the dissimilarity of the friction factor, f, against $\operatorname{Re}_{H}$ for the three longitudinal pitch cases. Figure 4(a) indicates that the friction factor decreases with the increase in the longitudinal pitch. The friction factor decreases with the increase in longitudinal tube pitch from 19.05 to $28.575 \mathrm{~mm}$ and 19.05 to $38.10 \mathrm{~mm}$, ( $21 \%$ and $34 \%$ respectively). It is evident from the figures that the pressure drop is indeed affected by the value of longitudinal pitch. The trend indicates that the pressure drop reduces as the value of the longitudinal pitch is increased. With the increase in longitudinal pitch, the flow mixing does not occur as often in the flow field. The increase in longitudinal pitch decreases the flow mixing and therefore the friction factor, similarly to the experimental work (Wang et al., 1996). The trend in Figure 4(b) indicates that there is a higher Colburn factor, $j$, for the low value of longitudinal pitch for each case of a Reynolds number. The Colburn factor decreases with the increase in longitudinal tube pitch from 19.05 to $28.575 \mathrm{~mm}$ and 19.05 to $38.10 \mathrm{~mm}(11 \%$ and $19 \%$ respectively). This phenomenon can be attributed to the assumption that at low longitudinal pitch, the fluid tends to mix well and there is thus greater absorption of heat from the walls. Another observation is that the difference in the value of the Colburn factor, in the cases of varied longitudinal pitch, lowers as the Reynolds number goes up. The efficiency index versus Reynolds number plot indicates that the efficiency index increases as the longitudinal pitch increases, as presented in Figure 4(c). This can be explained in that the efficiency of the heat exchanger depends on good heat transfer between the fluid and the fin and the low pressure drop of the flow. The Colburn factor decreases with the increase in longitudinal pitch. At the same time, the friction factor decreases with the increases in longitudinal pitch, but the efficiency increase when the percentage decreases in the friction factor is more than the percentage decrease in the Colburn factor. This means that as the flow becomes free with the increases in longitudinal pitch, the change of pressure is more significant than the heat transfer. This is why the efficiency index increases. 

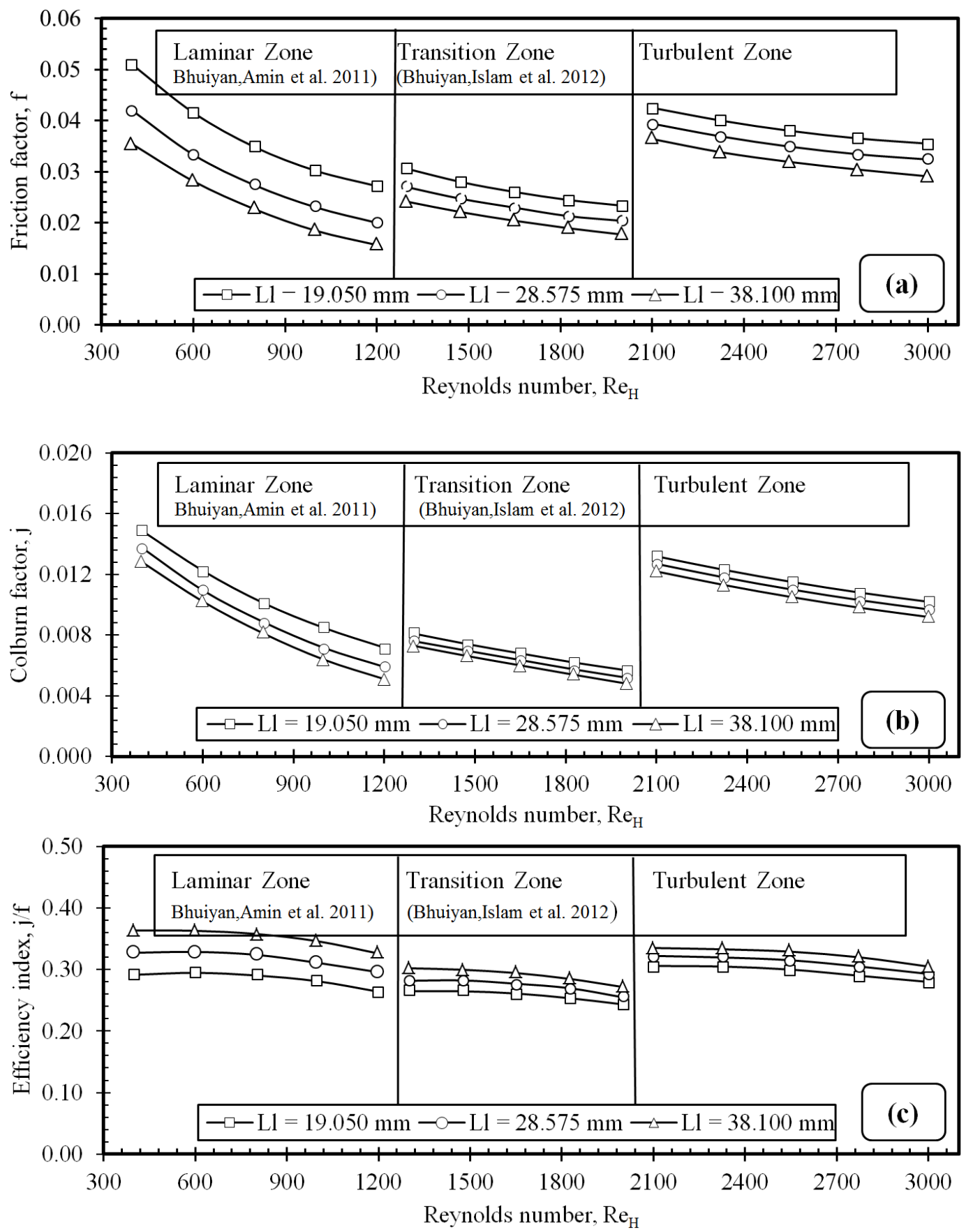

Figure 4. Effects of Longitudinal Pitch ( $\mathrm{Ll}$ ) for various flow regimes.

(a) Pressure Drop, (b) Heat Transfer and (c) Efficiency.

The effects of transverse tube pitch on the heat transfer and pressure drop performance for the same configuration have been analyzed for the turbulent flow range $\left(2100 \leq R e_{H} \leq 7000\right)$ by running three test cases. In each case, the transverse tube pitch $(L t)$ is changed, keeping all other geometrical parameters constant so that the effects of the transverse pitch over the heat exchanger performance can be analyzed. The same behavior has been observed for transverse pitch as for longitudinal pitch. 

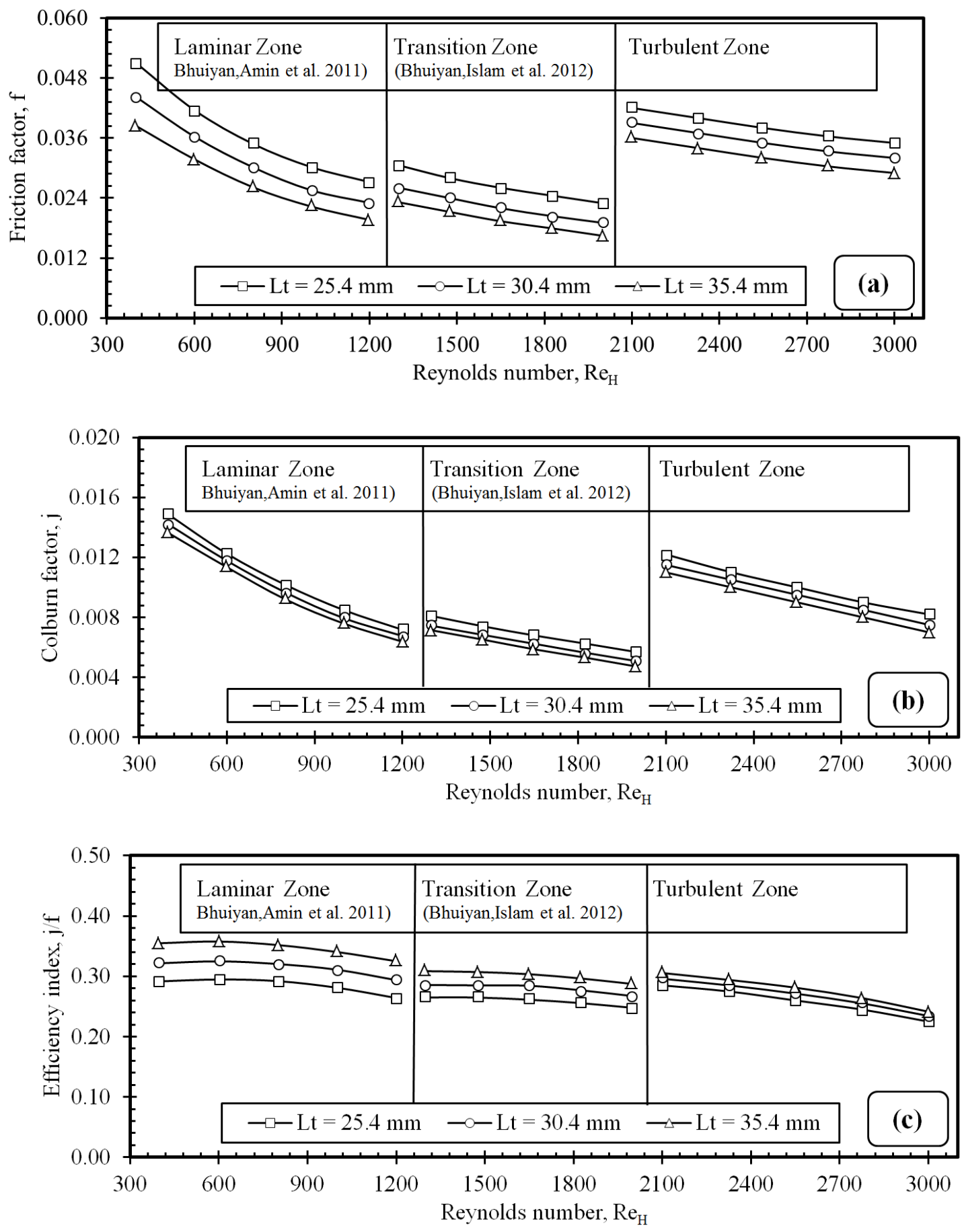

Figure 5: Effects of Transverse Pitch (Lt) for various flow regimes.

(a) Pressure Drop, (b) Heat Transfer and (c) Efficiency.

Figure 5(a) shows the characteristics of $f$ against $R e_{H}$ for variation of transverse tube pitch. The figure indicates that the friction factor goes down as the transverse tube pitch increases. The value of $f$ decreases with the increase of $L t$ from 25.4 to $30.4 \mathrm{~mm}$ and 25.4 to $35.4 \mathrm{~mm}$ (13\% and $25 \%$ respectively). Figure 5(b) shows the variation of the Colburn factor against the Reynolds number for the three transverse tube pitch cases. The figure indicates that the Colburn factor decreases with the increase in the transverse tube pitch. For a particular Reynolds number of $R_{H}=3000$, the Colburn factor 
decreases with the increase of transverse tube pitch from 25.4 to $30.4 \mathrm{~mm}$ and 25.4 to $35.4 \mathrm{~mm}$ (5\% and $9 \%$ respectively). The trend indicates that the pressure drop reduces as the value of transverse pitch is increased as longitudinal pitch. With the increase in transverse pitch, there is less flow mixing in the flow field. This singularity can also be attributed to the assumption that at low transverse pitch, the fluid tends to mix well and thus, has more absorption of heat from the walls.

The variation of efficiency index against $R e_{H}$ for different $L t$ is presented in the last plot of Figure 5(c). The efficiency index increases with the increase of transverse tube pitch from 25.4 to $30.4 \mathrm{~mm}$ and 25.4 to $35.4 \mathrm{~mm}$ ( $7.88 \%$ and $15.93 \%$ respectively). This can be explained in that the efficiency of the heat exchanger depends on good heat transfer between the fluid and the fin and the low pressure drop of the flow. The Colburn factor decreases with the increases of transverse tube pitch. At the same time, the friction factor decreases with the increases of longitudinal tube pitch. The efficiency increases, as the percentage decreases in the friction factor, is more than the percentage decrease in the Colburn factor. This means as the flow becomes free with the increases of transverse pitch the change in pressure is more significant than heat transfer. This is why the efficiency index increases. There is a significant effect of fin pitch on the friction factor as shown in Figure 6(a). The fin spacing strongly influences the overall pressure drop and therefore the friction factor. The figure indicates the variation of the friction factor against the Reynolds number for various fin pitch cases. The figure indicates that the friction factor decreases with the decrease in the fin pitch. For $R_{H}=$ 3000 , the friction factor decreases with the decrease of fin pitch from 3.53 to $2.53 \mathrm{~mm}$ and $3.531 .53 \mathrm{~mm}$ ( $21 \%$ and $36 \%$ respectively). This statement can be explained in that longitudinal pitch and transverse tube pitch are kept constant; when fin pitch is reduced the flow becomes more streamlined. This flow streamlining caused by the reduction in fin pitch simplifies the flow and creates better flow mixing. Reduction in the fin pitch also reduces the tube surface area which affects the friction factor. The inference is that if the fin spacing is too high, the pressure drop tends to increase and therefore the friction factor also increases. If the fin spacing is too small, the pressure drop is less.

Figure 6(b) indicates that the Colburn factor decreases with the decrease in fin pitch. The Colburn factor decreases with the decrease of fin pitch from 3.53 to $2.53 \mathrm{~mm}$ and 3.53 to $1.53 \mathrm{~mm}$ ( $7 \%$ and $16 \%$ respectively). This observation can also be explained on the basis of flow streamlining and the flow simplification keeping the longitudinal pitch and transverse tube pitch constant while the fin pitch is reduced. The flow simplification reduces the heat transfer performance. The reductions in fin pitch effects the heat transfer area and thus minimizes the Colburn factor. A higher heat transfer is observed for higher values of fin pitch. The effect subsides as the Reynolds number increases. It can also be seen from the figure that the efficiency index increases with the decreases in fin pitch. This observation suggests that even though the heat transfer performance decreases with the decrease in fin pitch, the efficiency for the surface increases due to the corresponding decrease in the friction factor. The pressure drop and the heat transfer both decrease with the decrease in the fin pitches for the plain fin staggered configuration, but the percentage decrease in the heat transfer performance is lower than the percentage decrease in the pressure drop. As a result the efficiency index increases with the decrease in the fin pitches. 

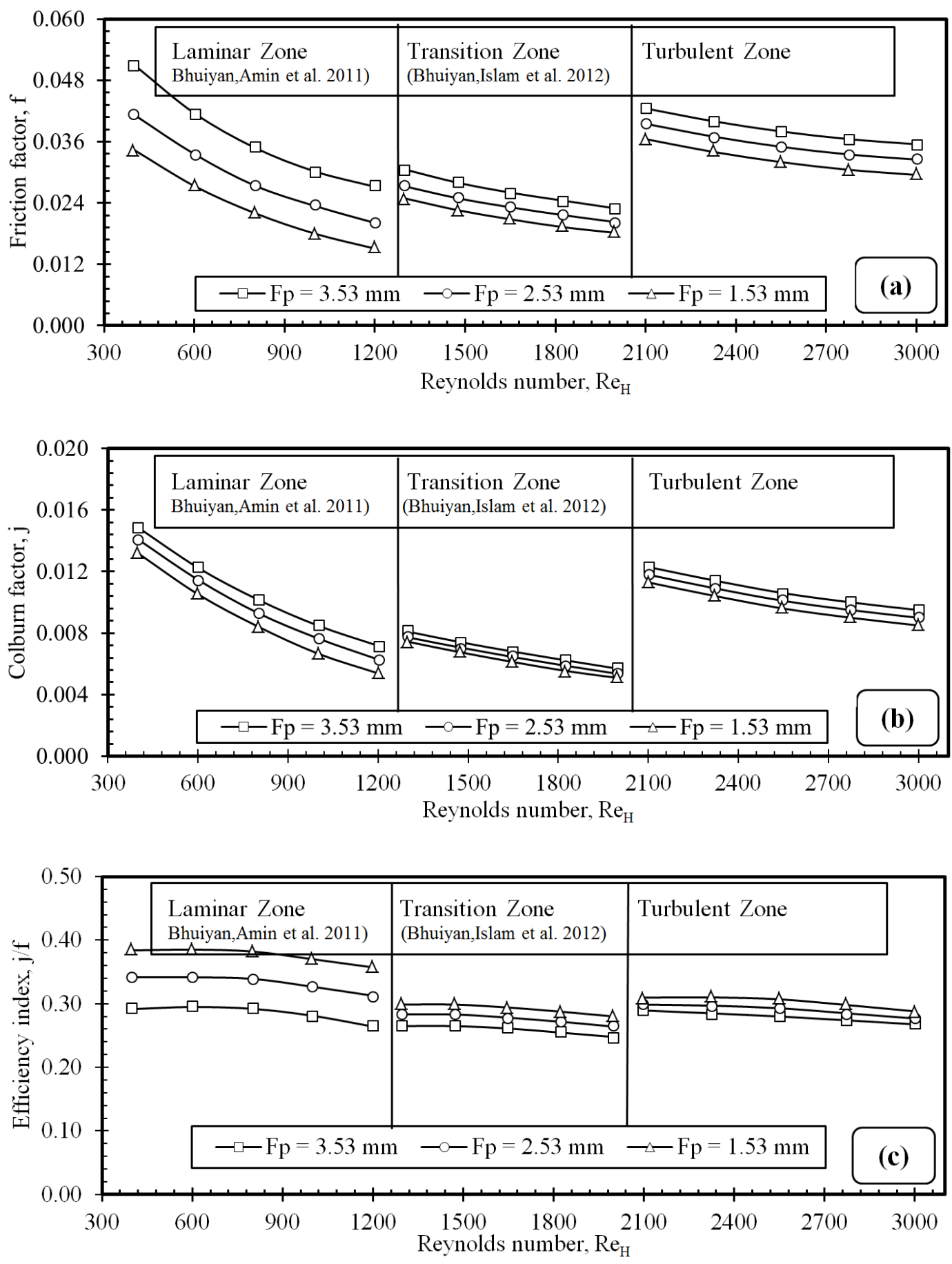

Figure 6: Effects of Fin Pitch (Fp) for various flow regimes.

(a) Pressure Drop, (b) Heat Transfer and (c) Efficiency.

\section{CONCLUSIONS}

Numerical investigations of heat transfer and pressure drop for a turbulent flow regime were carried out in this study. A K-Omega Turbulence model was employed for the flow range with 5\% turbulence intensity. The effect of flow distinction between plain fin staggered and an inline arrangement is significant. The findings can be concluded as follows: 
a) The increase in the longitudinal pitch causes a decrease in heat transfer and pressure drop performance as the flow becomes free and less compact with the increase in the tube pitch. As the pressure drop decrease is more significant than heat transfer, so the efficiency increases with the increase in tube pitch.

b) It was found, as with the effects of longitudinal pitch that with the increase in the transverse pitch there is a decrease in heat transfer and pressure drop performance. As the flow becomes less compact with the increase in the transverse pitch, $f$ and $j$ decrease.

c) The effect of fin pitch on the heat exchanger performance demonstrates that the decrease in the fin pitch shows opposite performance to the longitudinal and transverse pitches. As the fin pitch decreases, the flow becomes more streamlined. It affects the heat transfer performance as well as pressure drop characteristics. The efficiency index increases with the decrease in the fin.

\section{ACKNOWLEDGEMENT}

The authors would like to acknowledge the support of Islamic University of Technology, Dhaka, Bangladesh and Montana State University Bozeman, USA for providing laboratory facilities.

\section{REFERENCES}

Aslam Bhutta, M. M., Hayat, N., Bashir, M. H., Khan, A. R., Ahmad, K. N., \& Khan, S. (2012). CFD applications in various heat exchangers design: A review. Applied Thermal Engineering, 32, 1-12.

Bhuiyan, A., Islam, A., \& Amin, M. (2012a). Numerical study of 3D thermal and hydraulic characteristics of wavy fin-and-tube heat exchanger. Frontiers in Heat and Mass Transfer, 3( 033006 ), 1-9.

Bhuiyan, A. A., Amin, M. R., \& Islam, A. (2012b). Three-dimensional performance analysis of plain fin tube heat exchangers in transitional regime. Applied Thermal Engineering., 50(1), 445-454.

Bhuiyan, A. A., Islam, A. S., \& Amin, M. R. (2011). Numerical prediction of laminar characteristics of fluid flow and heat transfer in finned-tube heat exchangers. Innovative Systems Design and Engineering, 6(2), 1-12.

Chen, C. J., \& Wung, T. S. (1989). Finite analytic solution of convective heat transfer for tube arrays in crossflow: Part 2-heat transfer analysis. Journal of heat transfer. Journal of Heat Transfer, 111(3), 641-648.

Chiu, Y. W., \& Jang, J. Y. (2009). 3d numerical and experimental analysis for thermalhydraulic characteristics of air flow inside a circular tube with different tube inserts. . Applied Thermal Engineering, 29(2), 250-258.

Choi, J. M., Kim, Y., Lee, M., \& Kim, Y. (2010). Air side heat transfer coefficients of discrete plate finned-tube heat exchangers with large fin pitch. Applied Thermal Engineering, 30(2), 174-180.

Eckels, P., \& Rabas, T. (1987). Dehumidification: On the correlation of wet and dry transport processes in plate finned-tube heat exchangers. Journal of Heat Transfer 109(3), 575-582.

Fujii, M., Fujii, T., \& Nagata, T. (1984). A numerical analysis of laminar flow and heat transfer of air in an in-line tube bank. Numerical Heat Transfer, 7(1), 89-102.

Goldstein Jr, L., \& Sparrow, E. (1976). Experiments on the transfer characteristics of a 
corrugated fin and tube heat exchanger configuration. Journal of Heat Transfer, $98,26$.

Jang, J. Y., Wu, M. C., \& Chang, W.-J. (1996). Numerical and experimental studies of three dimensional plate-fin and tube heat exchangers. International Journal of Heat and Mass Transfer, 39(14), 3057-3066.

Junqi, D., Jiangping, C., Zhijiu, C., Yimin, Z., \& Wenfeng, Z. (2007). Heat transfer and pressure drop correlations for the wavy fin and flat tube heat exchangers. . Applied Thermal Engineering, 27(11), 2066-2073.

Kayansayan, N. (1993). Heat transfer characterization of flat plain fins and round tube heat exchangers. . Experimental Thermal and Fluid Science, 6(3), 263-272.

Kundu, D., Haji-Sheikh, A., \& Lou, D. (1991). Heat transfer predictions in cross flow over cylinders between two parallel plates. Numerical Heat Transfer, 19(3), 361-377.

Launder, B., \& Massey, T. (1978). The numerical prediction of viscous flow and heat transfer in tube banks. Journal of Heat Transfer, 100, 565.

Lu, J., Chen, T., Wu, J., Chris Wilson, P., Hao, X., \& Qian, J. (2011). Acid tolerance of an acid mine drainage bioremediation system based on biological sulfate reduction. Bioresource Technology, 102(22), 10401-10406.

Menter, F. R. (1994). Two-equation eddy-viscosity turbulence models for engineering applications. AIAA Journal, 32(8), 1598-1605.

Nakonieczny, K. (2006). Numerical modeling of cross-flow plate-fin air-to-air heat exchanger under unsteady flow conditions. Numerical Heat Transfer, Part A: Applications, 49(1), 1-24.

Panse, S. (2005). A numerical investigation of thermal and hydraulic characteristics in $3 D$ plate and wavy fin-tube heat exchangers for laminar and transitional flow regimes. (M. Sc. Thesis), Montana State University, , Bozeman, Montana,USA.

Pongsoi, P., Pikulkajorn, S., Wang, C. C., \& Wongwises, S. (2012). Effect of number of tube rows on the air-side performance of crimped spiral fin-and-tube heat exchanger with a multipass parallel and counter cross-flow configuration. International Journal of Heat and Mass Transfer, 55(4), 1403-1411.

Reddy, J. N., \& Gartling, D. K. (2010). The finite element method in heat transfer and fluid dynamics. USA: CRC press

Şahin, B., Akkoca, A., Öztürk, N., \& Akilli, H. (2006). Investigations of flow characteristics in a plate fin and tube heat exchanger model composed of single cylinder. . International Journal of Heat and Fluid Flow, 27(3), 522-530.

Syam Sundar, L., Sharma, K. V., \& Parveen, S. (2009). Heat transfer and friction factor analysis in a circular tube with $\mathrm{Al}_{2} \mathrm{O}_{3}$ nanofluid by using computational fluid dynamics. International Journal of Nanoparticles, 2(1), 191-199.

Tang, L. H., Min, Z., Xie, G. N., \& Wang, Q. W. (2009). Fin pattern effects on air-side heat transfer and friction characteristics of fin-and-tube heat exchangers with large number of large-diameter tube rows. Heat Transfer Engineering, 30(3), 171-180.

Tutar, M., \& Akkoca, A. (2004). Numerical analysis of fluid flow and heat transfer characteristics in three-dimensional plate fin-and-tube heat exchangers. Numerical Heat Transfer, Part A: Applications, 46(3), 301-321.

Wang, C.-C., Chang, Y.-J., Hsieh, Y.-C., \& Lin, Y.-T. (1996). Sensible heat and friction characteristics of plate fin-and-tube heat exchangers having plane fins. International Journal of Refrigeration, 19(4), 223-230.

Yuan, Z. (2000). Numerical study of periodically turbulent flow and heat transfer in a 
channel with transverse fin arrays. International Journal of Numerical Methods for Heat \& Fluid Flow, 10(8), 842-861.

Zhang, J. F., He, Y. L., \& Tao, W. Q. (2009). 3D numerical simulation on shell-andtube heat exchangers with middle-overlapped helical baffles and continuous baffles-part i: Numerical model and results of whole heat exchanger with middle-overlapped helical baffles. International Journal of Heat and Mass Transfer, 52(23), 5371-5380.

\section{NOMENCLATURE}

$\begin{array}{lll}\mathrm{C}_{\mathrm{P}} & \mathrm{J} / \mathrm{kg} \mathrm{K} & \text { Specific heat at constant pressure } \\ \mathrm{D} & \mathrm{m} & \text { Tube diameter } \\ \mathrm{Fp} & \mathrm{m} & \text { Fin pitch } \\ \mathrm{Ft} & \mathrm{m} & \text { Fin thickness } \\ \mathrm{f} & & \text { Friction factor } \\ \mathrm{H} & \mathrm{m} & \text { Fin spacing } \\ \mathrm{h} & \mathrm{W} / \mathrm{m}^{2} \mathrm{~K} & \text { Average heat transfer coefficient } \\ \mathrm{j} & & \text { Colburn factor } \\ \mathrm{k} & \mathrm{m}^{2} / \mathrm{s}^{2} & \text { Turbulence kinetic energy } \\ \mathrm{L} & \mathrm{m} & \text { Flow length } \\ \mathrm{Ll} & \mathrm{m} & \text { Longitudinal tube pitch } \\ \mathrm{Lt} & \mathrm{m} & \text { Transverse tube pitch } \\ \mathrm{m} & \mathrm{kg} / \mathrm{s} & \text { Mass flow rate } \\ \mathrm{Nu} & & \text { Nusselt Number } \\ \mathrm{P} & \mathrm{Pa} & \text { Local pressure } \\ \mathrm{Pin} & \mathrm{Pa} & \text { Inlet pressure } \\ \mathrm{Pk} & \mathrm{kg} / \mathrm{m}^{3} \mathrm{~s}^{3} & \text { Share production of turbulence } \\ \mathrm{Pr} & & \text { Prandtl Number } \\ \mathrm{Re} & & \text { Reynolds number based on fin spacing, } \rho \mathrm{H} / \mu \\ \mathrm{T} & { }^{\circ} \mathrm{C} & \text { Temperature } \\ \mathrm{T}_{\mathrm{in}} & { }^{\circ} \mathrm{C} & \text { Inlet temperature } \\ \mathrm{T}_{\mathrm{Wall}} & { }^{\circ} \mathrm{C} & \text { Wall temperature } \\ \mathrm{u} & \mathrm{m} / \mathrm{s} & \text { Velocity } \\ \mathrm{u}_{\mathrm{in}} & \mathrm{m} / \mathrm{s} & \text { Inlet(frontal) velocity } \\ \varepsilon & \mathrm{m} 2 / \mathrm{s}^{3} & \text { Turbulence dissipation rate } \\ \mathrm{k} & \mathrm{W} / \mathrm{m}^{\circ} \mathrm{K} & \text { Thermal conductivity } \\ \mu & \mathrm{Ns} / \mathrm{m}^{2} & \text { Dynamic viscosity } \\ \mu_{\mathrm{T}} & \mathrm{Ns} / \mathrm{m}^{2} & \text { Turbulent viscosity } \\ \rho & \mathrm{kg} / \mathrm{m}^{3} & \text { Fluid density } \\ & & \end{array}$

